\title{
Haben Sie mal 'ne Flasche Bier?
}

- Während des Stuttgarter Volksfestes hatte ich eine Haftfähigkeitsuntersuchung bei einer ca. 45-jährigen Frau durchzuführen. Diese hatte am frühen Sonntagmorgen auf dem Cannstatter Wasen heftig getrunken und Passanten angepöbelt. Als sie dann eine leere Bierflasche nach einer jungen Frau geworfen hatte, stellte diese Strafanzeige und die Betrunkene wurde mir zur Haftfähigkeitsuntersuchung vorgestellt.

Die Frau stand breitbeinig und schwankend vor mir und beantwortete die Frage nach der Alkoholmenge mit "eine Flasche Bier". Nein, mehr sei es nicht gewesen.
Weitere Fragen beantwortete sie widerwillig, weitschweifig und zum Teil auch unverständlich.

Dann sagte sie unvermittelt "Sie sind doch Arzt, oder?" Ich bejahte. „Haben Sie eine Flasche Bier in Ihrem Arztkoffer?" Ich antwortete, dass ich zwar viele Dinge dabei hätte, aber kein Bier. Nach Kreislaufkontrolle und orientierender neurologischer Untersuchung hakte sie dann noch einmal nach "Haben Sie wenigstens einen Kaffee dabei?"

DR. MEd. RAINER HAKIMI, STUTTGART .

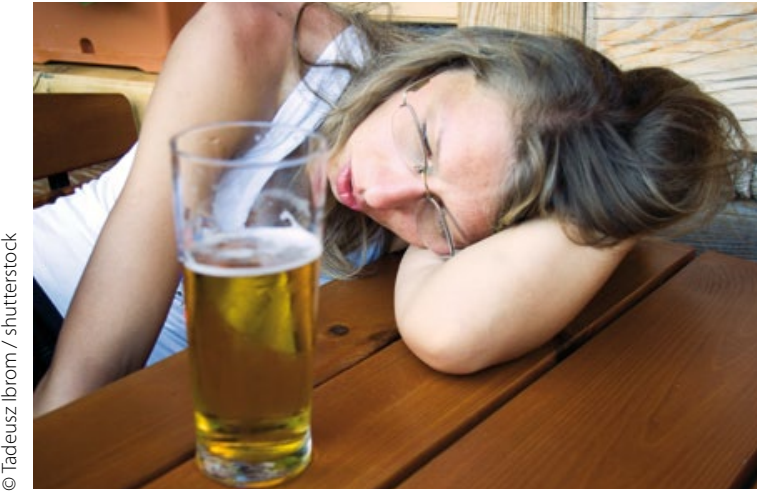

Warum hat der Doktor nichts zu Trinken dabei?

\section{Urlaubsschnäppchen}

- So ein Urlaub steckt doch immer wieder voller Überraschungen. Da hatte ich geglaubt, meine Zähne könnten dem Angriff eines alten französischen Baguettes standhalten, musste jedoch leidvoll feststellen, dass die Franzosen das bessere Material hatten. Ein Backenzahn war hinüber. Daraufhin stellte sich für mich die Frage, ob die Franzosen auch die besseren Zahnärzte stellen könnten?

Ich suchte einen französischen Dentisten auf, der allerdings Rache für Waterloo nahm und den Zahn nach vorherigem Röntgen und Setzen einer Anästhesie kurzerhand zog. Danach folgte für mich eine noch größere Urlaubsüberraschung, nämlich die Rechnung für die Arbeit des Zahnarztes: Ganze $42 €$ hatte ich zu berappen. Als Hamburger mit schwäbischem Migrationshintergrund war ich da fast geneigt, mir schnell noch einen Zahn ziehen zu lassen!

DR. MED. UDO FUCHS, HAMBURG .

\section{Bei Anruf - Mord!}

- Während der Facharztausbildung wurde ich im Nachtdienst auf die Männerstation gerufen. Ein älterer Patient litt unter Luftnot. Damals gab es noch 4-Bett-Zimmer. Daher hatte die Schwester nur die kleine Beleuchtung angemacht, damit die anderen Patienten nicht aufwachten.

Die Untersuchung des Patienten ergab, dass er Sauerstoff benötigte. Da es noch keine Sauerstoffanlagen in den Zimmern gab, holten wir eine mobile mannsgroße Sauerstoffflasche und bauten das System schnell zusammen. Wegen des schlechten
Lichts bemerkte ich aber nicht, dass ein Schlauch abgeknickt war und sich ein zwischengeschalteter Gummibeutel aufblähte. Plötzlich knallte es furchtbar laut, als der Beutel platzte.

In die Ruhe hinein rief plötzlich ein anderer Patient: „Jetzt haben sie ihn erschossen!"

Der alte Mann hat es aber doch noch überlebt.

\section{Gehorsame Patientin}

- Als die letzte Patientin heute zur Tür hereinschaute, war ich mächtig geschafft und freute mich auf die Mittagspause. So ganz einfach war das mit dieser Dame nicht immer, so befürchtete ich auch jetzt neue Herausforderungen.

"Ich fühle mich sehr gut!", sagte sie nun überraschend. „Ich hatte gestern leichte Beschwerden beim Wasserlassen. Aber dann habe ich mir eine Wärmeflasche genommen und viel getrunken, und jetzt ist es wieder völlig in Ordnung". Ich schlug vor, sicherheitshalber eben noch eine Urinprobe zu untersuchen, aber das lehnte sie ab. „Wieso denn, es geht mir doch bestens!" sagte sie.

Daraufhin wollte ich wissen, warum sie denn noch gekommen sei. „Das musste ich ja“, sagte sie treuherzig. „Ich hatte doch einen Termin!"

DR. med. Frauke Höllering, ARNSBerg = 